\title{
Experiences of incorporating support for early childhood development into the Baby Friendly Community Initiative in rural Kenya
}

\author{
Teresa Mwomal, Patricia Kitsao-Wekulo2, \\ Emma Haycraft ${ }^{3}$, Elizabeth Kimani-Murage ${ }^{2,7,8,9,10}$, Milka Wanjohi ${ }^{2}$, \\ Judith Kimiywe ${ }^{1}$, Esther Kinuthia ${ }^{2}$, Peter Muriuki ${ }^{4}$, \\ Natalie Pearson ${ }^{3}$, Kenneth Okelo ${ }^{2}$, Silas Onyango ${ }^{2}$, Oscar Kadenge ${ }^{5}$, \\ Betty Samburu, Stephen Mwangi ${ }^{6}$, Stewart Kabaka ${ }^{6}$, \\ Charity Tauta ${ }^{6}$ and Paula Griffiths ${ }^{3}$
}

Abstract: Over 66 per cent of children in sub-Saharan Africa remain affected by poor developmental outcomes, exacerbating early inequalities. UNICEF and WHO evolved the Care for Child Development package (CCD) as a community-based initiative to support caregivers to develop stronger relationships with young children and support nurturing care. The Baby Friendly Community Initiative (BFCI) is a global WHO strategy to promote optimal maternal, infant and young child nutrition at the community level. This paper provides insights into the feasibility and lessons learned from rural Kenya in providing CCD training and supporting its implementation alongside the BFCI. Findings from qualitative interviews with caregivers and implementers of the BFCI revealed that training community health volunteers on $\mathrm{CCD}$, enabled them to deliver CCD messages alongside those of the BFCI during counselling sessions. However, a more integrated approach to training as well as practical training opportunities, refresher training and provision of materials that facilitate the programme will enable further support for nurturing care in Kenya.

Keywords: Baby Friendly Community Initiative, Care for Child Development, caregiving, community initiatives, early childhood development, nurturing care, rural Kenya.

(C) The author(s) 2020. This is an open access article licensed under a

Creative Commons Attribution-NonCommercial-NoDerivs 4.0 Unported License

\footnotetext{
${ }^{1}$ Kenyatta University, Kenya. ${ }^{2}$ African Population and Health Research Center (APHRC), Kenya. ${ }^{3}$ Loughborough University, UK. ${ }^{4}$ University of Global Health Equity, Rwanda. ${ }^{5}$ PATH. ${ }^{6}$ Ministry of Health, Kenya. ${ }^{7}$ Wellcome Trust, UK. ${ }^{8}$ Brown University, USA. ${ }^{9}$ University of Glasgow, UK. ${ }^{10}$ Stellenbosch Institute for Advanced Study (STIAS), Wallenberg Research Centre at Stellenbosch University, South Africa.
} 


\section{INTRODUCTION}

Research has shown that the period from conception up to three years after birth lays the foundation for a child's health, well-being and productivity that lasts throughout childhood, adolescence and adulthood (for example, Hepper 2015, Lagercrantz 2016, WHO et al. 2018). This early period in development is characterised by rapid brain development with neuronal connections being made in response to a child's interactions with physical and social environments, both in utero and postnatally (Hepper 2015, Lagercrantz 2016; WHO et al. 2018). Development in this earliest period of life influences the child's health, learning and productivity as well as social and emotional well-being (for example, Campbell et al. 2014, WHO et al. 2018).

\subsection{The Care for Child Development package}

It is estimated that 43 per cent of children under 5 years of age are at risk of failing to achieve their human potential; in sub-Saharan Africa this proportion rises to 66 per cent (Daelmans et al. 2016, Lucas et al. 2017,). The WHO and UNICEF developed the Care for Child Development package to address this risk. The Care for Child Development package provides the basis for support and training to improve sensitive and responsive caregiving and promote psychosocial development of young children as part of its integrated management of child illnesses strategy.

Responsive caregiving encourages a caregiver to be responsive and to interpret and respond appropriately to a child's behaviour, including their movements, sounds and gestures. It is also the foundation for protecting children from injury, supporting appropriate responses to illness, nurturing early learning, and building personal, social and emotional skills (Black \& Aboud 2011, Lucas et al. 2017). The Care for Child Development package therefore aims to support caregivers to build strong relationships with their young children (Ainsworth et al. 1974, Lucas et al. 2017). Caregivers are observed interacting with their children. Counsellors then respond to the interaction that they have observed by counselling the caregiver using appropriate counselling cards from the Care for Child Development package. This helps parents and caregivers to increase the time spent with their children, thus improving the quality of interactions, with the potential to improve the child's learning and health (Lucas et al. 2017). Another important element of the programme is for counsellors to use the counselling to enable the caregiver to feel confident and to offer praise. The counsellor supports the caregiver to use child-directed language and to select appropriate and enjoyable activities that the caregiver and the child can do together at home to support play, communication, motor, cognitive and socio-emotional development. Play is encouraged, supported by locally relevant materials, such as tin cups, empty 
plastic containers, cooking pots and spoons, so that it is low cost and readily available (Lucas et al. 2017). Evidence shows that caregivers involved in the kind of counselling supported by the Care for Child Development strategy gain confidence and that this encourages positive changes in parenting behaviour (Aboud \& Akhter 2011). The counselling of caregivers may happen individually at home or in group settings, such as health facilities or community meetings (Aboud \& Akhter 2011, Lucas et al. 2017).

\subsection{The Baby Friendly Community Initiative}

Appropriate infant and young child nutrition is critical for optimal growth and development (WHO 2000). Poor nutrition is associated with negative outcomes in the child's cognitive development, morbidity in later life and reduced overall economic productivity (Victoria et al. 2008). The World Health Organization (WHO) recommends exclusive breastfeeding for the first six months of a child's life, with continued breastfeeding coupled with appropriate complementary feeding for up to 2 years of age, in order to meet the infant's growth and development needs (WHO 2002).

In Kenya, poor infant and young child nutrition remains a major challenge. According to the 2014 Kenya Demographic Health Survey (KDHS), stunting levels are at 26 per cent, while severe stunting is at 12 per cent among children aged 18 to 23 months. Additionally, the KDHS indicates that only 22 per cent of children in Kenya are fed in accordance with the recommended infant and young child feeding practices (KDHS 2014). Rural Kenya records high levels of global acute malnutrition, primarily attributable to poor child-feeding practices, poor health-seeking behaviour, and poor sanitation and hygiene (UNICEF 2016).

In order to address poor infant and young child nutrition, improve health and reduce mortality, the child survival and development strategy in Kenya aims to accelerate and scale-up evidence-based, high-impact interventions (Kenya Ministry of Health 2013). The Kenyan government, through the Ministry of Health, implemented the Baby Friendly Hospital Initiative, developed by the WHO and UNICEF in 1990, in order to address the poor breastfeeding practices in maternity wards. This initiative places emphasis on implementation at the hospital level, promoting breastfeeding in hospitals worldwide. However, the impact of the Baby Friendly Hospital Initiative in less developed countries like Kenya, where more than half of womenespecially the poor-deliver at home, is limited (KNBS 2009, Montagu et al. 2011). Therefore, following the urgent need to transfer the benefits of the Baby Friendly Hospital Initiative to the community, Kenya explored the adoption of the Baby Friendly Community Initiative in rural settings (Kimani-Murage et al. 2015). The Baby Friendly Community Initiative was introduced to expand on the tenth step of the Baby Friendly Hospital Initiative: to focus on supporting breastfeeding mothers 
after they leave hospital. In Kenya, the Baby Friendly Community Initiative aims to protect, promote and support breastfeeding, complementary feeding, maternal nutrition (using locally available foods), and appropriate sanitation and hygiene (Casanovas \& Saadeh 2009, Kenya Ministry of Health 2016). The Baby Friendly Community Initiative is delivered primarily through activities such as: establishment of mother-tomother support groups; cooking demonstrations; home counselling visits with community health volunteers; inclusion of spouses and grandmothers in support groups; and the introduction of income-generating projects such as kitchen gardens (Masibo \& Kimani 2014, USAID-MCHIP 2013). Knowledge of appropriate breastfeeding duration, amount of food to feed according to age, recommended food groups, and feeding during illness have been used as indicators to develop messages for use when counselling mothers. Nutrition messages are coupled with messages promoting good health, such as following an appropriate schedule of vaccinations and promoting appropriate hygiene and sanitation practices. The major strategy for sustaining the Baby Friendly Community Initiative programme in Kenya depends upon a wellcoordinated multi-sectoral approach with various components: (a) capacity building of healthcare providers, communities and other relevant stakeholders; (b) regular supportive supervision and mentoring; and, (c) advocacy and monitoring and evaluation through proper documentation by the Ministry of Health in collaboration with partners.

\subsection{Theoretical domains framework}

Behaviour change is key to improving healthcare and health outcomes (Cane et al. 2012). According to Cane and colleagues, behaviours may be those of healthcare workers, such as the implementation of evidence-based practices, including medication adherence in patients or increased physical activity in the general population. Improving the implementation of evidence-based practice by healthcare workers therefore depends on changing multiple behaviours of multiple types of people, including health professionals (Cane et al. 2012, Grol \& Grimshaw 2003). Changing behaviour is not easy, but it is more effective if interventions are based on evidence as well as on principles of behaviour change (Abraham et al. 2009).

To facilitate new practices, there is a need for all important influencers to change their behaviours as well as to understand both current and desired behaviours and their determinants (Atkins et al. 2017). Behavioural theories therefore provide an explicit statement of structural and physiological processes hypothesised to regulate behaviour and behaviour change relevant to implementation problems and implementation interactions (Atkins et al. 2017). 
The theoretical domains framework (Atkins et al. 2017) was initially developed to support research around the implementation of evidence-based recommendations. The framework provides a theory through which behaviour can be understood. Atkins et al. (2017), Cane et al. (2012) and Michie et al. (2005) synthesised thirty-three theories of behaviour and behaviour change into fourteen domains, as outlined in Table 1.

The theoretical domains framework is relevant to this paper as it provides clear pathways between structural and psychological processes linked to behavioural regulation and behaviour change. The framework is therefore important for understanding the implementation and incorporation of new practices. Furthermore, evidence suggests that implementation and/or behaviour change is more successful if there is a theoretical underpinning.

Little is known about how best to incorporate messages and practices relating to nurturing care into the Baby Friendly Community Initiative in the rural Kenyan context. For the successful implementation of an integrated nurturing care programme into the Baby Friendly Community Initiative, it is imperative to understand its feasibility from the perspective of relevant users and deliverers of such a programme (that is, healthcare workers and caregivers) within the context that the programme will be delivered. Implementing or incorporating new practices and/or changing or adapting existing practices in services and systems require changes in the understanding and behaviours (or practices) of relevant stakeholders. This is facilitated by an understanding of the influences of current and desired behaviours and practices within the context in which they occur.

\subsection{Aims}

This paper aims to provide an understanding of the feasibility of and lessons learned from rural Kenya in providing Care for Child Development training and implementation alongside the existing health- and nutrition-focused Baby Friendly Community Initiative programme. 
Table 1. The domains and constructs of the theoretical domains framework. (Source: Atkins et al. 2017)

\begin{tabular}{|c|c|c|}
\hline Domain & $\begin{array}{l}\text { Explanation/definition of } \\
\text { domain }\end{array}$ & Construct \\
\hline Knowledge & $\begin{array}{l}\text { an awareness of existence of } \\
\text { something }\end{array}$ & $\begin{array}{l}\text { knowledge of condition; procedural } \\
\text { knowledge; knowledge of task } \\
\text { environment }\end{array}$ \\
\hline Skills & $\begin{array}{l}\text { ability or proficiency acquired } \\
\text { through practice }\end{array}$ & $\begin{array}{l}\text { skills development; ability; } \\
\text { interpersonal skills; practice; skills } \\
\text { assessment }\end{array}$ \\
\hline $\begin{array}{l}\text { Social/professional and } \\
\text { role identity }\end{array}$ & $\begin{array}{l}\text { a coherent set of behaviours } \\
\text { and displayed personal } \\
\text { qualities of an individual in a } \\
\text { social or work setting }\end{array}$ & $\begin{array}{l}\text { professional identity; professional } \\
\text { role; social identity; professional } \\
\text { boundaries; professional confidence; } \\
\text { group identity; leadership; } \\
\text { organisational commitment }\end{array}$ \\
\hline Beliefs about capabilities & $\begin{array}{l}\text { acceptance of the truth, } \\
\text { reality or validity about an } \\
\text { ability, talent or facility that a } \\
\text { person can put to constructive } \\
\text { use }\end{array}$ & $\begin{array}{l}\text { self-confidence; perceived } \\
\text { competence; self-efficacy; perceived } \\
\text { behavioural control; beliefs; } \\
\text { self-esteem; empowerment; } \\
\text { professional confidence }\end{array}$ \\
\hline Optimism & $\begin{array}{l}\text { the confidence that things will } \\
\text { happen for the best or that } \\
\text { desired goals will be attained }\end{array}$ & $\begin{array}{l}\text { optimism; pessimism; unrealistic } \\
\text { optimism; identity }\end{array}$ \\
\hline Beliefs about consequences & $\begin{array}{l}\text { acceptance of the truth, reality, } \\
\text { or validity about outcomes of } \\
\text { behaviour in a given situation }\end{array}$ & $\begin{array}{l}\text { outcome expectancies; characteristics } \\
\text { of outcome expectancies; anticipated } \\
\text { regrets, consequences }\end{array}$ \\
\hline Reinforcement & $\begin{array}{l}\text { Increasing the probability of } \\
\text { a response by arranging a } \\
\text { dependent relationship or } \\
\text { contingency between the } \\
\text { response and given stimulus }\end{array}$ & $\begin{array}{l}\text { rewards; incentives; punishment; } \\
\text { consequences; reinforcement, } \\
\text { sanctions }\end{array}$ \\
\hline Intentions & $\begin{array}{l}\text { a conscious decision to } \\
\text { perform a behaviour or } \\
\text { resolve to act in a certain way }\end{array}$ & $\begin{array}{l}\text { stability of intentions; stages of } \\
\text { change model; and stages of change }\end{array}$ \\
\hline Goal & $\begin{array}{l}\text { mental representations of } \\
\text { outcomes or end states that } \\
\text { an individual wants to achieve }\end{array}$ & $\begin{array}{l}\text { goal priority; goal/target setting; } \\
\text { action planning; implementation } \\
\text { intention }\end{array}$ \\
\hline $\begin{array}{l}\text { Memory, attention and } \\
\text { decision processes } \\
\text { control; }\end{array}$ & $\begin{array}{l}\text { ability to retain information, } \\
\text { focus selectively on aspects of } \\
\text { the environment and choose } \\
\text { between two or more } \\
\text { alternatives }\end{array}$ & $\begin{array}{l}\text { memory; attention; attention } \\
\text { control; decision making; } \\
\text { cognitive overload/tiredness }\end{array}$ \\
\hline $\begin{array}{l}\text { Environmental contexts and } \\
\text { resources }\end{array}$ & $\begin{array}{l}\text { any circumstances of a person's } \\
\text { situation or environment that } \\
\text { discourages or encourages the } \\
\text { development of skills and } \\
\text { abilities, independence, social } \\
\text { competence and adaptive } \\
\text { behaviour }\end{array}$ & $\begin{array}{l}\text { environmental stressors; resource/ } \\
\text { material resources; organisational/ } \\
\text { culture climate; salient events/critical } \\
\text { incidents; persons vs environment } \\
\text { interactions, barriers and facilitators }\end{array}$ \\
\hline
\end{tabular}


Table 1. Continued.

\begin{tabular}{|c|c|c|}
\hline Social influence & $\begin{array}{l}\text { those interpersonal processes } \\
\text { that can cause individuals to } \\
\text { change their thoughts, feelings } \\
\text { or behaviours } \\
\text { modelling; alienation }\end{array}$ & $\begin{array}{l}\text { social pressure; social norms; group } \\
\text { conformity; social comparisons; } \\
\text { group norms; social support; power; } \\
\text { intergroup conflict; group identity; }\end{array}$ \\
\hline Emotion & $\begin{array}{l}\text { a complex reaction pattern, } \\
\text { involving experiential, } \\
\text { behavioural and physiological } \\
\text { elements by which the individual } \\
\text { attempts to deal with a personally } \\
\text { significant matter }\end{array}$ & $\begin{array}{l}\text { fear; anxiety; affect; stress; } \\
\text { depression; positive/negative affect; } \\
\text { burn-out }\end{array}$ \\
\hline Behavioural regulation & $\begin{array}{l}\text { anything aimed at managing } \\
\text { or changing objectively } \\
\text { observed or measured actions }\end{array}$ & $\begin{array}{l}\text { self-monitoring; breaking habit; } \\
\text { action plan }\end{array}$ \\
\hline
\end{tabular}

\section{METHOD}

This paper is based on the qualitative component of a larger study whose overall aim was to evaluate the potential impact of the Baby Friendly Community Initiative intervention on early childhood development in relation to cognitive, physical and socio-emotional outcomes. The study sought to establish whether supporting nutrition and health in infancy has additional benefits for early childhood development outcomes and the feasibility of incorporating parental support for child stimulation into the Baby Friendly Community Initiative.

\subsection{Study design}

This paper presents results from qualitative data gathered from stakeholders, caregivers and implementers of the integrated Baby Friendly Community Initiative and Care for Child Development package in rural Kenya. The purpose of the qualitative study was to determine the feasibility of incorporating Care for Child Development messages into the Baby Friendly Community Initiative and to obtain feedback on the proposed format of the Care for Child Development materials within the Baby Friendly Community Initiative. The study also sought to determine the ordering of materials for successful implementation and monitoring of the Care for Child Development elements of the programme.

\subsection{Participants}

We employed purposive sampling to select participants for this study. The participants included county and sub-county officials, community health extension workers, community health volunteers, early childhood development experts and practitioners, 
Baby Friendly Community Initiative stakeholders (including representatives from the Ministry of Health) and caregivers of young children (including fathers, mothers and grandmothers). We conducted seven focus group discussions (FGDs), thirty-six key informant interviews (KIIs) and six in-depth interviews (IDIs), as well as a stakeholder meeting at the end of the project. The breakdown of the participants in the qualitative interviews is provided in Table 2. Supportive supervision reports from community health extension workers who supervise community health volunteers were also analysed to identify challenges that the community health volunteers faced in delivering the intervention messages in the field given their low levels of education. In total, thirty community health volunteers were trained on the Care for Child Development package - twelve male and eighteen female, ranging in age from late twenties to early sixties. These workers were all members of the communities in which they were working and had a minimum of eight years of primary education and a maximum of four years of secondary education.

Table 2. Participants in the qualitative interviews.

\begin{tabular}{lccc}
\hline \multirow{2}{*}{ Participants } & \multicolumn{3}{c}{ Type of interview } \\
\cline { 2 - 4 } & FGDs & KIIs & IDIs \\
\hline Fathers & 2 & & 1 \\
Mothers & 2 & & 1 \\
Grandmothers & 1 & & 1 \\
Community health volunteers & 2 & 13 & 3 \\
ECD teachers & & 12 & \\
ECD service providers & 3 & \\
Community health extension workers & & 4 & \\
Sub-county leaders & & 2 & \\
County leaders & & 1 & \\
Village elder & & $\mathbf{3 6}$ & $\mathbf{6}$ \\
Head of ECD organisation & $\mathbf{7}$ &
\end{tabular}

\subsection{Ethical considerations}

The study protocol was reviewed for scientific and methodological soundness by the African Population and Health Research Center (APHRC) internal scientific review committee. Ethics approval was sought and obtained from the Amref Health Ethics and Scientific Review Committee. A study permit was obtained from the National Commission for Science, Technology and Innovation (NACOSTI). Further ethical approval was obtained through Loughborough University ethics committee. Prior to conducting the interviews, we sought informed consent from the study participants. Only participants who provided their informed consent were included in the study. 


\subsection{Data collection and analysis}

Prior to data collection, the research team (comprising researchers from the APHRC and Kenyatta and Loughborough Universities) developed semi-structured interview/ focus group guides in relation to the stated objectives. The interview/focus group guides focused on areas such as: potential barriers and facilitators to the implementation of Care for Child Development and the Baby Friendly Community Initiative at the individual, provider and policy levels; current community parental support practices for Care for Child Development; lessons learned from continual engagement with the stakeholders during the project; the experiences of delivering Care for Child Development training from lead trainers at the national level through to grassroots training; and supervision reports of community health volunteers delivering Care for Child Development messages as part of the existing Baby Friendly Community Initiative package. The questions were intended to align with salient aspects of the theoretical domains framework namely: knowledge; skills; social/professional and role identity; beliefs about capabilities; reinforcement (that is, use of rewards/punishments and understanding of consequences); memory, attention and decision processes; environmental contexts and resources (that is, circumstances, situation or environment that promote or hinder the development of skills and abilities); and social influence (that is, the interpersonal processes that can facilitate behaviour change, such as building rapport). The interview/focus group guides were developed in English and later translated by a professional translator into the local language.

To enhance the quality of the data, experienced qualitative field interviewers were recruited and trained prior to data collection. Interview guides were piloted to check the appropriateness of items as well as to ensure that they were culturally meaningful. A debrief meeting was subsequently held to revise the guides and to ensure that all the items were appropriate. The field protocol was adapted, as appropriate.

Interviews were scheduled at the participant's convenience. All the interviews and FGDs were conducted in the local language and by field interviewers who were conversant with the language. The interviews with government officials were conducted in English by research team members. The duration of the qualitative interviews ranged from 30 minutes for KIIs to up to one-and-a-half hours for FGDs. The field team was closely supervised by the research team with regular debriefs.

All of the interviews and FGDs were audio recorded. The data were then translated and transcribed verbatim and analysed through thematic analysis using a deductive approach. This was done by reading the transcripts and listening to the recording for validation. Each transcript was coded according to the thematic areas which were organised around the domains of the theoretical domains framework. The similarities 
and contrasts within the data were compared by the research team in the coding process during a two-day data-coding review meeting. Similarities and differences in coding were addressed in the meeting before analysis commenced.

\section{RESULTS}

This section presents the results of the study with a focus on the community health volunteers' and caregivers' knowledge, skills and practices after training the community health volunteers to deliver the Care for Child Development package as part of the Baby Friendly Community Initiative package in rural Kenya.

3.1 Community health volunteers' knowledge, skills and practices on Care for Child Development

\subsubsection{Community health volunteers' knowledge on play and stimulation}

After receiving the training on Care for Child Development, community health volunteers reported that they had gained knowledge on play and stimulation (Table 3). They learned that stimulation begins during the perinatal period when the child is still in the womb. They reported that they were also made aware that, when breastfeeding, a mother is able to stimulate her child's hearing through talking. Such behaviour facilitates bonding and attachment between the mother and the baby, which in turn enhances the child's social and emotional development. Hence, mothers were encouraged to talk to their babies during breastfeeding. They also learned the importance of including fathers in play. The community health volunteers further revealed that they learned that, at birth, babies are able to see an object located up to 12 inches away (Table 3).

Through training on Care for Child Development, community health volunteers have become aware of the importance of play in relation to the child's development. According to them, they learned that play enhances children's cognitive and physical development and promotes healthy development in children. Community health volunteers reported that they use age-appropriate, locally available materials to play with the child as a way of creating rapport. The use of locally available materials was encouraged during training. The volunteers also encouraged caregivers to use locally available materials to play with their children. Community health volunteers also learned the importance of praising caregivers as a result of the Care for Child Development training. They reported that, whenever they discovered that the caregiver was aware of what they were teaching, they praised them and encouraged them to continue practising it. 
During training, community health volunteers were provided with a simple checklist to observe the interaction between the caregiver and the child, to facilitate prompting of the caregiver by asking questions to understand how the caregiver plays and communicates with the child as they record. Community health volunteers reported that they found the checklists which they were provided with during the training on the Care for Child Development package to be useful.

After the Care for Child Development training, the community health volunteers reported that they were able to train caregivers on the importance of exclusive breastfeeding during the first six months. They taught caregivers how to hold the baby when breastfeeding whilst also encouraging play and stimulation, thereby integrating messages from both the Care for Child Development package and the Baby Friendly Community Initiative. Community health volunteers also reported that they had learned that colostrum is rich in nutrients which support the baby's development and that is why they encourage mothers to exclusively breastfeed babies immediately after birth (Table 3).

Table 3. Community health volunteers' knowledge, skills and practices on Care for Child Development and infant feeding.

\section{Knowledge on play and stimulation}

Care for Child Development is beginning from when helshe is still in the stomach. Even if you touch - if the mother touches like this [rubbing stomach]; I mean, helshe moves because helshe can hear. And again, the mother must be comfortable. Because if she has a disturbance; I mean being scolded and has stress, then the child becomes stressed too.

(FGD with community health volunteers)

Now when you are breastfeeding him/her, you talk to him/her. I mean when you are talking to him/ her, you will know if this child truly is active or is not active. It means-for me I understand it as to make friendship with a child since when helshe is small, you become his/her friend, stay close to him/her, play with him/her, talk with him/her and you will help that child to develop.

(FGD with community health volunteers)

So when helshe has been born, first you see if the child can see. You move your finger, 12 inches, helshe sees... his/her eyes twists, it goes around like this... Again, a child when helshe is growing, helshe feels, I mean attachment. Helshe tries to move because helshe has seen, has felt.

(FGD with community health volunteers)

\section{Importance of play}

When you play with him/her, you will see if the hands have any problem. When you give him/her something and helshe stretches the hand to you, you will truly know if the hands are okay or not okay. And then, again, when helshe continues to grow, when helshe moves even on the legs, you will see truly if the legs of that child are okay, or not okay. According to me, Care for Child Development helps the child to develop in the brain; muscles especially in this part of the hand [showing], it helps that.

(FGD with community health volunteers) 
Table 3. Continued.

And it is true that the fathers were not coming close to the child. They were saying a small child belongs to the mother. Because even when we arrive at households, if you ask if they play with the child, they say it is the mother who usually plays with the child. But after the training, I saw that even the father has taken his space.

(FGD with community health volunteers)

\section{Age-appropriate play with use of locally available play materials}

You take those materials when going for the visit, when you reach a place where you get a child depending on the age; you show the child, the mother or the caregiver that [material]. This thing can help the child to play ... when helshe is trying to knock like this. For example, something like a spoon; you tell her, give [the child] something like a spoon to knock-knock like this. When helshe is knocking it like that, helshe is trying to get the sound of that thing; and also muscle development.

(FGD with community health volunteers)

A child of less than one year, you give him/her things to play with; maybe of putting inside a container or hitting. And then a child who has not reached one year; you can give him/her shakers or things to hold and look at. And a small child who maybe is not able to hold something; you can give him or her things to stretch the hands, and to look at so that you can see whether helshe is seeing or hearing. You can shake sideways or in front of him/her, if you want to know if helshe is hearing you can shake both, so that helshe tries to turn like this; and then that very small child of one week to six months; you can just give [materials] of looking at because helshe cannot hold; helshe will just look at it. Then you will know helshe can see.

(FGD with community health volunteers)

\section{Using checklists to record observations}

[The] checklist is what helps us to know if the counselling card has worked. Because when you arrive at a household, you look at a child and then you record what you see and then there is a place where you ask and listen so that you can know if helshe has known what you have taught. And if helshe has known, you praise him/her. So you will ask her the name, and then as you teach you will be ticking there in the counselling card. If she has told you that the child is four years, now you go there and indicate what is in there. You will go to the checklist and indicate age; for example, there where it is written 'child under six months'.

(FGD with community health volunteers)

\section{Knowledge of feeding practices}

I think [the] Baby Friendly Community Initiative is exclusive breastfeeding. The child must be breastfed exclusively immediately after being born. So [the] Baby Friendly Community Initiative and Care for Child Development go together because the child must be breastfed for six months and then the things of Care for Child Development enter inside. It is done together.

(FGD with community health volunteers)

When you are positioning, and how you hold the child. When you breastfeed the child as shelhe is looking at you. You breastfeed as you talk to him/her as helshe is looking at you. So, I see that Baby Friendly Community Initiative and Care for Child Development enter there.

(FGD with community health volunteers)

I have even known that, the colostrum - when a child is breastfed, it contains a lot of nutrients. Now it has taught me because those are things I had not known. So I have really learnt.

(FGD with community health volunteers) 


\subsubsection{Community health volunteers' skills in practice and social relations}

The community health volunteers reported the importance of creating rapport at the beginning of the counselling session with the caregiver and infant. They revealed the practices they used to facilitate this. They reported that, when they got to the household, they began the session by introducing themselves and then explaining the purpose of their visit before counselling the caregiver. They asked caregivers to demonstrate to them how they play with the baby, and congratulated them, before starting to counsel them. Community health volunteers recognised that praising the interaction between the caregiver and the child is one way of motivating caregivers to continue playing with their child. Community health volunteers revealed that, in order to further create rapport with caregivers and infants whenever they visited families for counselling, they carried with them play materials which they had made from locally available raw materials. The materials helped them to trigger the infant's interest in the play activities while they counselled the caregivers. Using such a strategy facilitated engagement with the caregiver on the topic of play and stimulation (Table 4).

Several community health volunteers were able to articulate how the Care for Child Development training had improved their social and professional standing within the community. This had in turn improved their confidence to support the nurturing care of infants. The community leaders demonstrated confidence in the community health volunteers by, for example, inviting them to talk to parents on supporting early child development (ECD) at the village chiefs' barazas (meetings). Community health volunteers reported that they are applying the knowledge gained in the interactions that they have with their own children. They also felt that the training had made them become important social influencers as role models on care for child development within their communities (Table 4).

Community health volunteers revealed that, as a result of the Care for Child Development training, they felt more confident in encouraging caregivers to use locally available play materials, such as household objects like spoons, metal plates and plastic cups and bottles, as play objects for their children. They also reported having better capabilities to help caregivers to form play partnerships with their infants by ensuring that the play environment and materials were safe and conducive for children.

Table 4. Skills and roles of the community health volunteers.

\section{Creating rapport}

We were taught that when we are starting to counsel parents or families, first we greet them and then we do our introduction and then we tell her to start playing with the child. They should speak to the child and feed him/her well and play with him/her. And then if they are doing well, we appreciate. 
Table 4. Continued.

Now you take those materials when you are going for that visit, so that when you reach a place where you get a child depending on the age, you show the child and the mother or the caregiver. I will ask her how she is playing with the child. The way she will tell me, if she knows I will congratulate her for doing that. And if she will not know, I will tell her the importance of playing with the child and why she should play with the child. And when she is there and she does not have anything of buying for the child, she can even make it at home.

(FGD with community health volunteers)

\section{Social/professional role identity, confidence and influence}

Me on the side of training, it was able to build me. I got to be recognised in the community, they have liked maybe the teachings I have taught, and even in those meetings which are in Barrazas, maybe even the church I get an opportunity to give out a message. It will be my happiness when I will see that the child is growing mentally, health-wise, and maybe she has been favoured and loved by the community.

(FGD with community health volunteer)

We communicate with him a lot. Because I tell him [inaudible chanting], he does like this, when I tell him 'eat', he says [inaudible]. Then you say, you know that he wants food. Before we were not concerned with matters of playing with children; we did not have time. But these days we are understanding there is a benefit for playing with children. How to show him even to shake things, he gets a different knowledge. Even when he kicks a ball, again he gets practice. The body becomes flexible and he gets good health. We have seen benefits from them that we were not getting those days.

(FGD with community health volunteers)

\section{Community health volunteers' beliefs and capabilities to counsel}

I am very much grateful because it has assisted me personally as an ECD teacher and again, I have become courageous when I usually meet a caregiver with a child. I already have a message of giving it to her at all times. I no longer fear. I really have confidence to do everything. Yes, I see it is good. I see it is good because I am a grandmother of many grandchildren and when I come to where I am, they know that grandmother likes playing. That time they come to play. Yes, them coming to me, they know they will get many teachings.

(interview with a community health volunteer/ECD teacher)

For me, when I arrive at the child's mother, or the caregiver, first I ask how they play with the child. Now at my place, I have a mother who has a child of one week. ... Now I have taught them how to be close with the child and to be really skin to skin. So I made shakers so that the time I am going; I go and play with children. Even at home, I called groups of women and we went and helped the children with the mothers. I taught them until even we made materials of playing with a child.

(FGD with community health volunteers)

\subsection{Caregivers' knowledge, skills and practice on Care for Child Development}

\subsubsection{Caregivers' knowledge on care for child development}

Through counselling by community health volunteers on Care for Child Development, caregivers (mothers, fathers and grandmothers) reported that they had acquired knowledge about the importance of playing with their infants during pregnancy and 
after birth. The counselling helped fathers and grandparents to understand that the tradition of them not being involved with the infant was not good for the infant's development. Mothers reported that they learned the importance of playing with their children and that, through playing, children learn how to imitate tasks and later learn how to do those tasks. They gave examples of locally available play materials that children can play with. Mothers also learned the importance of praising their babies whenever they do something right (Table 5).

\subsubsection{Caregivers' knowledge on children's communication and language development}

Mothers and fathers revealed that, through counselling, they had learned that talking to the child helps the child learn how to speak, while playing with him/her helps in acquiring social skills. The social skills in turn enhance brain development. Mothers further reported that, after counselling, they were more likely to label objects, animals and people in the environment to enhance their infants' language development (Table 5).

\subsubsection{Caregivers' skills and capabilities in Care for Child Development}

Through counselling, mothers reported that they had gained knowledge and skills about utilising local materials to fashion play objects for their infants, as well as about the importance of creating time to play with their children. Mothers also reported that they had learned new tactics to encourage babies to walk such as calling out to them (the children) going towards them (mothers), or reaching out to the child. Mothers reported that the counselling cards were an important tool for helping them understand the Care for Child Development messages from pregnancy into the early years of a child's life (Table 5).

\subsubsection{Caregivers' knowledge on nutrition}

Interviews with both mothers and fathers revealed that they had retained knowledge regarding optimal infant feeding practices after the training on care for child development: that is, the new training had not taken away knowledge from their original training on the Baby Friendly Community Initiative. This finding suggested that the community health volunteers were able to incorporate counselling on optimal infant feeding practices into the support for Care for Child Development. For example, mothers, fathers and grandmothers reported that, through counselling and community information days, they had learned the importance of exclusive breastfeeding in the first six months (Table 5). 
Table 5. Caregivers' knowledge, skills and practices on Care for Child Development.

\section{Caregiver knowledge on care for child development}

The mother should respond when helshe plays in the womb or the father; both parents to cooperate in the development of this child. Again a child when helshe is born, we must play with him/her, we must give him/her good nutrition and playing with that child helps the child's neck and bones to be strong. And again when helshe is breastfed and spoken to, it helps bonding between the mother and the child.

(FGD with mothers)

You can go and hide yourself by a tree, and the child, pretends to be looking for you. At the same time, you can go behind the child and then you try to speak, so that helshe will try to find you. Another thing; you can hold something like [inaudible], like this, you show him/her. So when you are stretching it towards the child, helshe is learning, that attraction when the child is trying to hold that thing.

(interview with a father)

Even me, it has become of benefit to me very much because when we were being taught there, I started with my grandchild of my son's wife, when she came home. Now I started to teach her and to show her how to care for that child, and to play with. And I made for her those objects of playing with. So she was very happy even when she is there in Nairobi she calls me and says 'how many have you made?'. I tell her, 'it is there, come and take'. I made for those of my neighbours who are young. Many times they come to my home, and we make them; they stay very close to me. And I see that it's a very important thing. And I monitor those I have taught as we continue together.

(FGD with grandmothers)

Sometimes when she does that, I tell her, 'good girl'. I clap for her there, she even likes it, I repeat like that, I tell her, 'good girl', like that.

(IDI with a mother)

\section{Involvement of other caregivers besides the mother in care for child development}

Now us men, we did not know the responsibility of caring for a child. Caregiving was only for mothers ... we gave the mother her work, when she has delivered, she continues with her child. But, after the training, we knew that this care for child development brings everyone closer to the child.

(FGD with fathers)

In the past, we never used to play with children. We believed that this would make them old. Now after the Care for Child Development teachings, we are more confident about playing with children.

(FGD with grandmothers)

\section{Caregiver knowledge on communication and language development}

To play and to communicate with a child means development for the child. Let us say, the child starts to develop in the brain and helshe starts again to look at the environment, to see how things can be in the environment. 
Table 5. Continued.

You can tell him/her to call the name father, mother, or you can tell him/her to call his/her name. It is almost the same. Only that if I tell him/her to bring me something ... like a cup, you tell him/ her to bring a cup and tell him/her how it is used. You associate some things with how they are used. Yes, it is like that.

\section{Caregiver knowledge on nutrition}

(FGD with mothers)

I used to breastfeed [the child] like thirty minutes it was enough. But [the community health volunteer] told me about one hour, stay with your child; breastfeeding him/her. You know even me. I wasn't able to deal with the child, those thirty minutes, then I run, I go to other activities. Then the Community Health Volunteer came and told me 'no', have time with your child first then other things to come later.

(FGD with mothers)

We talked about the time the child has been born, and how to feed the child from there is to give breast milk until like six months so that the child has energy, you must do breastfeeding first. After that you start feeding the child after six months. To feed him/her a little-a little with that food that is required so that helshe can get energy. You give him/her things like proteins carbohydrates and things like vitamins and fruits. All kinds.

(FGD with fathers)

In the past, grandmothers used to give their grandchildren traditional medicine before six months, but they now advocate for exclusive breastfeeding in their households.

(FGD with mothers)

\section{Mothers' belief in their ability to play and stimulate their babies}

... it is not a must you buy him/her things to play with. You just give him/her his/her things if they are clean to play with; you don't have to go to the shop to buy things to play with. You can show him/her bright colours ... that his/her eyes can like ... and then you make the things helshe plays with not to be small. Make them to be a little bigger and bright, that helshe loves.

(FGD with mothers)

At times the child can try to walk. You can tell him/her to stand with one leg; you can tell him/her run there and bring me a cup; you can tell him/her bring me a knife, a sieve, things like that.

(FGD with mothers)

\section{Care for Child Development tools}

I think at first when we were being taught things of stages, how a child is supposed to be played with, it was hard to understand it ... from which stage to which stage or how to use an object. But later when we were given that counselling card, it helped us very much. Because the time that we had was not very long for learning so many topics. But after going with that counselling card, it taught us.

(FGD with mothers) 
3.3 Challenges experienced by community health volunteers in implementing Care for Child Development

It was apparent from the supportive supervision reports provided by community health extension workers that various challenges were experienced by community health volunteers in implementing Care for Child Development training. The challenges that they reported included:

- Community health volunteers tended to forget what they had learned during the Care for Child Development training, particularly if they did not use the messages frequently.

- When a community health volunteer is transferred to a new community unit after having been trained on Care for Child Development and the Baby Friendly Community Initiative and the new unit does not have a trained supervisor (community health extension worker), the community health volunteer is not likely to apply the knowledge gained as the combination of lack of experienced supervision and the community health volunteer needing to familiarise themselves with the new households and caregivers result in an environment not conducive to delivering the intervention. This highlights the importance of supportive supervision in the process as well as not burdening community health volunteers with too many new parameters.

- Lack of regular documentation and reporting/monitoring of activities that community health volunteers were carrying out in the community in relation to implementation of Care for Child Development and the Baby Friendly Community Initiative meant that there was inadequate information on the programme implementation process.

- A gap in the knowledge around maternal infant and young child nutrition was noted among the community health volunteers, particularly with regard to complementary feeding. This could be attributed to the fact that, since the main aim of the earlier intervention was to improve breastfeeding practices, the initial training on the Baby Friendly Community Initiative emphasised messages on exclusive breastfeeding. Less time was therefore spent on training that focused on complementary feeding because of meagre training resources. Community health volunteers may not be very conversant with the recommended food groups, or with the frequency and quantity of feeds that should be given to babies when they are weaned. This highlights the importance of providing adequate time to train on each of the key messages of the Baby Friendly Community Initiative and Care for Child Development.

- During counselling sessions, it was observed that the community health volunteers would often place greater emphasis on Care for Child Development 
messages with little focus on the Baby Friendly Community Initiative/Maternal Infant and Young Child Nutrition messages. The focus on Care for Child Development messages was attributed to the fact that training on this aspect was more recent than that on the Baby Friendly Community Initiative.

- Community health volunteers may have felt overburdened by the need to concurrently deliver the combined Care for Child Development and Baby Friendly Community Initiative messages to caregivers.

- Some community health volunteers did not carry or use the Care for Child Development counselling materials during their visits and could therefore not rely on them as prompts for the guidance they should provide to caregivers in response to what they had observed.

- Some community health volunteers had not grasped specific key messages for each age group, leading them to dwell on caregivers' past practices which may not have been appropriate for the child's current age.

- Some fathers continued to face cultural challenges in publicly supporting their wives with child care, revealing the continued social and environmental constraints to optimal care.

Stakeholder engagement (with the trainers and with individuals from the county health department, community health extension workers and Ministry of Health) at the end of the project resulted in a number of suggestions to overcome the challenges faced by community health volunteers, as well as suggestions to improve the training (see Table 6). The suggestions focused on improving reporting tools, updating the counselling cards with simplified messages and more pictures, delivering regular supervision and mentorship of community health volunteers, and the provision of opportunities for more practice during the training of community health volunteers.

Table 6. Suggestions to mitigate challenges encountered and some recommendations for improving future Care for Child Development training.

\begin{tabular}{|c|c|}
\hline Area of practice & Suggestion/recommendation \\
\hline $\begin{array}{l}\text { A need for a combined } \\
\text { reporting tool for } \\
\text { community health } \\
\text { volunteers }\end{array}$ & $\begin{array}{l}\text { A reporting tool that combines content from both the Baby } \\
\text { Friendly Community Initiative and Care for Child } \\
\text { Development messages is needed for the community health } \\
\text { volunteers to document their work. } \\
\text { - An integrated checklist is required because having two } \\
\text { different checklists, one for Care for Child Development and } \\
\text { one for Baby Friendly Community Initiative, is cumbersome } \\
\text { and they are difficult to use concurrently. }\end{array}$ \\
\hline Updated counselling cards & $\begin{array}{l}\text { - Updated counselling cards and a simplified key-messages tool } \\
\text { should be developed as job aids for the community health } \\
\text { volunteers. }\end{array}$ \\
\hline
\end{tabular}


Table 6. Continued.

Community health volunteer supervision/ mentorship

Supporting fathers to embrace caregiving practices

Recommendations for community health volunteer training
- There is a need for the counselling cards to be more visually appealing than those with words alone.

- There is need for quarterly community health volunteer supervision to be led by the sub-county health management team. However, supervision by community health extension workers should be more regular. More contact between the sub-county health management team and community health extension workers is needed to build the capacity of the community health extension workers.

- Continual mentorship and close supervision of community health volunteers will likely encourage them to continue counselling caregivers. However, this can be an expensive venture and needs to be properly costed.

- There is need for community health volunteers to continue encouraging fathers to support their wives in caregiving.

- The training content should be tailored in such a way as to make the content very simple to understand in order to meet the needs of community health volunteers who are likely to have low levels of education. The current level of training was not always appropriate to the qualifications of a community health volunteer within the Kenyan context.

- There is a need to have more practical sessions during training to enable community health volunteers to acquire the necessary knowledge and skills on counselling in relation to Care for Child Development.

- The training materials and tools utilised should be summarised into a format that is simple and easy to grasp. Consideration should be given to including more pictures and illustrations in the training materials.

- The time allocated for practical sessions in the health facility, community and preschool was found to be insufficient for trainees to master the skill of counselling caregivers and playing with children. It may be helpful to allocate more time for practical observations, particularly for community health volunteers, since they are the ones who provide the counselling to caregivers in the community and schools.

\section{DISCUSSION}

The aim of this study was to provide an understanding of the feasibility and lessons learned from rural Kenya in providing Care for Child Development training and supporting its implementation alongside the existing health and nutrition focused Baby 
Friendly Community Initiative programme. The paper is based on the findings obtained through interviews with caregivers (mothers, fathers and grandparents), stakeholders and community health volunteers, as well as the monitoring notes of community health extension workers.

The findings revealed that, in addition to the training on the Baby Friendly Community Initiative provided two years earlier, training on Care for Child Development resulted in community health volunteers and their supervisors being able to articulate key messages from both programmes/packages. Community health volunteers were also able to demonstrate the skills that they had acquired to support effective implementation of the Care for Child Development messages. These skills included making toys with locally available materials and beginning their counselling sessions with observations of the interactions between the mother and child to obtain opportunities for praise and learning. Community health volunteers also reported improved self-confidence in their own abilities and increased social status in the community as a result of the additional skills that they had gained through the training. Their participation in community meetings where they were engaged to impart knowledge on early childhood development had positive effects on fathers' involvement in nurturing care for their infants that went beyond individual counselling sessions. Greater involvement of fathers in early childhood care and development is particularly important in a context where, due to cultural norms, the care of young children is considered as 'women's work'.

The positive results notwithstanding, a number of barriers to successfully integrating the Care for Child Development and Baby Friendly Community Initiative were identified. It is of utmost importance to address these barriers in order to improve future intervention training and delivery.

\subsection{Knowledge}

Community health volunteers participated in Care for Child Development training to enhance their understanding on the importance of play and stimulation during early childhood. They were able to accurately talk about the importance of stimulation during pregnancy and feeding episodes as well as how to support play through the provision of locally relevant, age-appropriate materials. For instance, they could recall the Care for Child Development training message that the unborn baby can be stimulated through touching and massaging the mother's tummy and through speaking or singing to the foetus. This reinforces Hepper's assertions that the foetus first begins to experience the world through touch, and later in pregnancy begins to hear, taste, smell and see (Hepper 2015). 
Community health volunteers were able to articulate the relationship of play to brain development and to the development of motor skills and socio-emotional skills. They were also able to appreciate that children of different ages needed stimulation with different activities and materials because of their different developmental stages. The finding that caregivers also recognised the importance of play and stimulation for their infants' or young children's development illustrated that community health volunteers were successful in imparting the knowledge that they had obtained through the training. A number of caregivers were also able to report knowledge on the importance of optimal infant feeding, a finding which illustrated their ability to internalise messages from the original Baby Friendly Community Initiative intervention as well as the Care for Child Development package. This finding suggests that, for some caregivers, multiple messages can be delivered and understood.

Community health volunteers were also able to articulate the importance of observing feeding and play episodes in order to identify infants with potential developmental delays for referral to appropriate health services. These findings suggest that the capacity of low-cadre health professionals can be built to such a level that they are able to share these messages effectively. Caregivers can also gain knowledge about the importance of stimulation and play to improve early child development. This is important because, if the intervention is to be scalable and sustainable, it needs to be delivered by health workers who exist in sufficient numbers to be able to deliver this task.

\subsection{Skills}

Providing nurturing care to children through good nutrition, stimulation and play during the critical window of development between pregnancy and the first three years of life prepares them to grow, develop and fit well into their environment (WHO et al. 2018). In low-resourced settings, caregivers can receive the requisite knowledge on appropriate nurturing care through home visits provided by community health volunteers who are trained on integrated messages from the Care for Child Development and the Baby Friendly Community Initiative packages. We were keen to understand whether or not the training helped community health volunteers to gain the necessary skills to retain and integrate the combined messages during the home visits, because imparting knowledge does not necessarily translate into practice. The finding that a number of community health volunteers demonstrated an ability to retain and pass on knowledge from both the Baby Friendly Community Initiative and Care for Child Development trainings is evidence that strategies to integrate related messages are effective. 
The community health volunteers in the study area focused on supporting maternal and child health, which might explain why some were able to retain this knowledge as they were not being asked to work to support other health conditions or public health messages and were specialising in maternal and child health and development. These findings support the idea of supporting community health volunteers to work in specialist areas, such as nurturing care from conception to three years, rather than spreading knowledge thinly over several specialties. Campbell et al. (2014) maintain that the early developmental processes, and experiences in pregnancy through to age three, have been shown to significantly impact children's health, learning and productivity as well as social and emotional well-being. The effects last for the remainder of childhood and through to adolescence and adulthood. There is, therefore, good evidence that it is worthwhile to invest in providing community health volunteers with specific skills to support nurturing care through counselling caregivers. From our observations, it was apparent that some community health volunteers and caregivers were less able to retain all of the messages. This might be linked to the lack of supportive supervision that some community health volunteers received when a community health extension worker moved from one locality to another, or it could be due to the challenges in training and implementation. Further work is required to elucidate the specific influences contributing to this outcome.

The community health volunteers were able to internalise the importance of creating rapport with caregivers and their infants through strategies such as taking home-made toys to the home visit which they could use to engage the infant. They also articulated the importance of observing the caregiver and infant before counselling to identify behaviours that could be praised and used as an anchor for the counselling session. Caregivers were also able to articulate the importance of making toys available to the child using locally available materials. Using locally available materials to support play demonstrated support for Care for Child Development in this setting which in turn has the potential to enhance the social and emotional development of children. This is important because interpersonal skills are fostered through secure affective relationships with caregivers, and so abilities created in early childhood have lifelong effects on socio-emotional skills (Nofziger \& Rosen 2017).

\subsection{Social/professional role identity, confidence and social influence}

The community health volunteers reported that the additional training they received on Care for Child Development raised their status within the community and resulted in them being invited to contribute to community meetings to share their knowledge beyond individual counselling sessions. The resultant boost in their confidence and 
prestige within their local community facilitated involvement of the broader community in understanding and supporting the nurturing care messages. An unintended effect was that there was somewhat increased male involvement in nurturing care support, as community health volunteers reached out to them specifically. Fathers reported gaining both knowledge and a new understanding of their role in supporting the development of their offspring as a result of the messages the community health volunteers had communicated after the training. Overall, social influences remain a barrier to fathers' complete engagement in the nurturing care of their infants. Future interventions should consider including greater support for fathers as well as devising means of breaking down cultural and social barriers to fathers' involvement.

\subsection{Beliefs, capabilities and reinforcement}

The Care for Child Development training resulted in community health volunteers having stronger beliefs in their capabilities to support caregivers to interact with their children through play and to support play partnership formation through interaction with safe locally available toys and objects. The community health volunteers were also aware of the importance of reinforcement. They praised caregivers who engaged in good practices and also taught caregivers the importance of praising their child. Similar to the findings from other studies, caregivers were able to develop the habit of praising their children in order to reinforce appropriate developmental behaviours after receiving the Care for Child Development messages (Nofziger \& Rosen 2017). In this setting, after observing the caregiver, counsellors were able to capitalise on the information gained to counsel the caregiver using information given on counselling cards appropriate to the child's age.

\subsection{Challenges (and solutions) related to environmental contexts and resources}

The challenges reported in the interviews with stakeholders were identified at the individual, household, community and societal levels. Some of these challenges were related to personal and traditional beliefs surrounding the care of young children. Others were concerned with tailoring the training content to the level of the trainees, as well as the need for continuous training and supportive supervision, and improved monitoring and reporting tools.

It is noteworthy that the participants themselves were able to identify solutions to the identified challenges. For instance, the use of counselling cards with more visual cues than words was preferred by the community health volunteers, as this would simplify the messages and make them easier to understand. More opportunities for practical experiences during the training would also enhance the internalisation of the 
Care for Child Development messages. Continual supportive supervision was identified by community health extension workers as a way to provide ongoing support and regular feedback to enhance the delivery of these messages. In addition, an integrated reporting and monitoring tool, structured according to the age of the child, would promote ease of use and facilitate better monitoring of the programme. Such a tool would also be useful for the Ministry of Health and District Health Services which provide resources to the programme.

There is need for more opportunities for feedback to community health volunteers on their counselling skills to go beyond the training and include the implementation of the Baby Friendly Community Initiative and Care for Child Development training into their daily duties. Experiences from the field suggest that there is a need for two levels of supervision of the integrated programme. One level would be on a quarterly basis, between the sub-county health management team and the community health extension workers (supervisors of community health volunteers). At the lower level, community health extension workers would supervise community health volunteers on a monthly basis. Similar observations were made in Pakistan where Lady Health Workers (equivalent to community health volunteers) delivered a Care for Child Development intervention and were found to need more regular supervision (Gowani et al. 2014; Yousafzai et al. 2014, 2105). The cost of this 'extra' supervision needs to be ascertained to ensure that this would be feasible given the available resources in Kenya. There is need to deliver the programme at scale and this would require additional resources to train master trainers who are in short supply within the country. Another challenge is not having enough master trainers to take the Care for Child Development training to scale in Kenya. This will also require resources to train the master trainers to deliver the programme. The reliance on lower level health workers to deliver the programme means that supportive supervision, where mentorship can happen in everyday practical situations, is an important part of the learning and sustainability of the programme. We have demonstrated that, where regular supportive supervision is not available, community health volunteers are not able to retain and implement the counselling messages successfully. Supportive supervision is therefore a critical factor in scaling up the Care for Child Development training. This challenge has also been identified in other evaluations of the implementation of Care for Child Development in other low- and middle-income countries (Lucas et al. 2017)

Increasing the involvement of male caregivers requires overcoming the challenges that are informed by cultural beliefs and traditions. There are opportunities within the Baby Friendly Community Initiative model to address the topic on the importance of fathers as caregivers in supporting Care for Child Development. This could be done within community support groups and activities that are facilitated through village elders as part of the existing Baby Friendly Community Initiative package. When such 
messages come through the community leaders, there is likely to be a positive impact on male engagement in childcare, in particular, and resultant changes in social and cultural beliefs on male involvement in childcare in general.

\section{CONCLUSION}

Through engagement with the Ministry of Health in Kenya throughout this project we have learned that there is political will to support a nurturing care package to promote the optimal early child development of infants and young children. The main findings of this research have shown that training community health volunteers on the Care for Child Development package enabled them to deliver Care for Child Development messages alongside those of the Baby Friendly Community Initiative during counselling sessions in rural Kenya. The findings suggest that a more integrated approach to training, coupled with the provision of updated and refined materials that support the programme, would further improve the support for nurturing care. While there is some integration of support for early child development and nutrition and basic health messages in the 2016 version of the Care for Child Development package, community health volunteers report requiring more visually stimulating materials for better engagement with families. These materials need to be supported by regular monitoring and supervision of both the community health volunteers and their supervisors. Establishing the cost of such monitoring needs will better inform the potential feasibility of scaling-up this approach in rural Kenya where resources are limited.

In this study we have only been able to consider lessons learned and the potential feasibility of community health volunteers delivering both the Baby Friendly Community Initiative and Care for Child Development messages in a non-integrated training and implementation package. There also remains a need to study the potential effects of implementing a fully combined intervention within the Baby Friendly Community Initiative model, which includes community support for the intervention beyond individual counselling by community health volunteers. This would facilitate understanding of how this model would influence infant nutrition, growth and early child development in this rural Kenyan context.

\section{REFERENCES}

Aboud, F. E. \& Akhter, S. (2011), 'A Cluster-randomized Evaluation of a Responsive Stimulation and Feeding Intervention in Bangladesh', Pediatrics, 127: e1191-e1197.

https://doi.org/10.1542/peds.2010-2160 
Abraham, C., Kelly, M. P., West, R. \& Michie, S. (2009), 'The UK National Institute for Health and Clinical Excellence Public Health Guidance and Behaviour Change: A Brief Introduction', Psychology Health and Medicine, 14(1): 1-8. https://doi.org/10.1080/13548500802537903

Ainsworth, M. D. S., Bell, S. M. \& Stayton, D. J. (1974), 'Infant-Mother Attachment and Social Development: "Socialization" as a Product of Reciprocal Responsiveness to Signals", in The Integration of a Child into a Social World ed. M. P. M. Richards (Cambridge, Cambridge University Press), 99-135.

Atkins, L., Francis, J., Islam, R., O’Connor, D., Patey, A. M., Ivers, N. M., Foy, R., Duncan, E. M., Colquhoun, H., Grimshaw, J. M., Lawton, R. \& Michie, S. (2017), 'A Guide to Using the Theoretical Domains Framework of Behaviour Change to Investigate Implementation Problems', Implementation Science, 12(1): 77. https://doi.org/10.1186/s13012-017-0605-9

Black, M. M. \& Aboud, F. E. (2011), 'Responsive Feeding Is Embedded in a Theoretical Framework of Responsive Parenting', Journal of Nutrition, 141: 490-4. https://doi.org/10.3945/jn.110.129973

Campbell, F., Conti, G., Heckman, J., Moon, S.H., Pinto, R., Pungello, E. \& Pan, Y. (2014), 'Early Childhood Investments Substantially Boost Adult Health', Science, 243: 1478-85. https://doi.org/10.1126/science.1248429

Cane J., O'Connor D. \& Michie S. (2012), 'Validation of the Theoretical Domains Framework for Use in Behaviour Change and Implementation Research', Implementation Science, 7: 37. https://doi.org/10.1186/1748-5908-7-37

Casanovas C. \& Saadeh R. (2009), 'Scaling Up Protection, Protection and Support of Breastfeeding at the Community Level', Food Nutrition Bulletin, 30: S230-5. https://doi.org/10.1177/15648265090302S207

Daelmans, B., Darmstadt, G. L., Lombardi, J., Black, M. M., Britto, P., Lue, S., Bhutta, T. \& Richter, L. M. (2016), 'Early Childhood Development: The Foundation of Sustainable Development', The Lancet, 389(10064): 9-11. https://doi.org/10.1016/S0140-6736(16)31659-2

Gowani, S., Yousafzai, A. K., Armstrong, R. \& Bhutta, Z. A. (2014), 'Cost-effectiveness of Responsive Stimulation and Nutrition Interventions on Early Child Development Outcomes in Pakistan', Annals of the New York Academy of Sciences, 1306: 140-61. https://doi.org/10.1111/nyas. 12367

Grol R. \& Grimshaw J. (2003), 'From Evidence to Best Practice: Effective Implementation of Change in Patients' Care', The Lancet, 362: 1225-30. https://doi.org/10.1016/S0140-6736(03)14546-1

Hepper, P. (2015), 'Behaviour During the Prenatal Period: Adaptive for Development and Survival', Child Development Perspective, 9(1): 38-43. https://doi.org/10.1111/cdep.12104

KDHS (2014), 'Kenya Demographic and Health Survey 2014' (Nairobi, Government Printers).

Kenya Ministry of Health (2013), 'National Policy for Maternal Infant and Young Child Nutrition' (Nairobi, Kenya Ministry of Health).

Kenya Ministry of Health (2016), 'Baby Friendly Community Initiative: Implementation Guideline' (Nairobi, Ministry of Health).

Kimani-Murage E. W., Kimiywe J., Kabue M., Wekesah F., Matiri E., Muhia, Wanjohi M., Muriuki P., Samburu B., Kanyuira J. N. \& Young S. L. (2015), 'Feasibility and Effectiveness of the Baby Friendly Community Initiative in Rural Kenya: Study Protocol for a Randomized Controlled Trial', Trials, 16: 431. https://doi.org/10.1186/s13063-015-0935-3

KNBS (2009), 'Kenya Demographic and Health Survey 2008-2009' (Calverton, Maryland, Kenya National Bureau of Statistics and ICF Macro).

Lagercrantz H. (2016), Infant Brain Development: Formation of the Mind and the Emergence of Consciousness (Basel, Springer International).

Lucas, J. E., Richter, L.M. \& Daelmans, B. (2017), 'Care for Child Development: An Intervention in Support of Responsive Caregiving and Early Child Development', Child: Care Health, 44(1): 41-9. https://doi.org/10.1111/cch.12544 
Masibo P. \& Kimani E. (2014), 'Baby Friendly Community Initiative: A Desk Review of Existing Practices' (Nairobi, African Population and Health Research Center).

Michie, S., Johnston, M. \& Abraham, C. (2005), 'Making Psychological Theory Useful for Implementing Evidence Based Practice. A Consensus Approach', Quality and Safety in Health, 14(1): 26-33. https://doi.org/10.1136/qshc.2004.011155

Montagu, D., Yamey G., Visconti A., Harding A. \& Yoong J. (2011), 'Where do Poor Women in Developing Countries Give Birth? A Multi-country Analysis of Demographic and Health Survey Data', PLoS One, 6 : e17155. https://doi.org/10.1371/journal.pone.0017155

Nofziger, S. \& Rosen, N. L. (2017), 'Building Self-control to Prevent Crime', in B. Teasdale \& M. Bradley (eds) Preventing Crime and Violence (Basel, Springer International), 43-56.

https://doi.org/10.1007/978-3-319-44124-5_5

UNICEF (2016), 'Annual Report Kenya'.

https://www.unicef.org/about/annualreport/files/Kenya_2016_COAR.pdf

USAID-MCHIP (2013), 'Maternal and Child Health Integrated Program. Kenya's Baby-Friendly Community Initiative Improves Maternal and Infant Feeding Practices'.

Victora, C. G., Adair, L., Fall, C., Hallal, P. C., Martorell, R., Richter, L \& Sachdev, H. S. (2008), 'Maternal and Child Undernutrition: Consequences for Adult Health and Human Capital', The Lancet, 371: 340-57. https://doi.org/10.1016/S0140-6736(07)61692-4

WHO (2000), 'Nutrition for Health and Development: A Global Agenda for Combating Malnutrition' (Geneva, World Health Organization ).

WHO (2002), 'The Optimal Duration of Exclusive Breastfeeding. Report of an Expert Consultation' (Geneva, World Health Organization ).

WHO, United Nations Children's Fund \& World Bank Group (2018), 'Nurturing Care for Early Childhood Development: A Framework for Helping Children Survive and Thrive to Transform Health and Human Potential' (Geneva, World Health Organization).

Yousafzai, A. K., Rasheed, M. A., Rizvi, A., Armstrong, R. \& Bhutta, Z. A. (2014), 'Effect of Integrated Responsive Stimulation and Nutrition Interventions in the Lady Health Worker Programme in Pakistan on Child Development, Growth, and Health Outcomes: A Cluster-randomised Factorial Effectiveness Trial', The Lancet, 384: 1282-93. https://doi.org/10.1016/S0140-6736(14)60455-4

Yousafzai, A. K., Rasheed, M. A., Rizvi, A., Armstrong, R. \& Bhutta, Z. A. (2015), 'Parenting Skills and Emotional Availability: An RCT', Pediatrics, 135: e1247-57.

https://doi.org/10.1542/peds.2014-2335

\section{Notes on the authors}

Teresa Mwoma is a Senior Lecturer at Kenyatta University in the Department of Early Childhood and Special Needs Education. She was a Co-Principal Investigator for the British Academy funded early childhood development research project that informed this paper. Teresa is the National Coordinator, Early Childhood Development Network Kenya and a Research Associate in the Faculty of Education University of Johannesburg South Africa. She is a DAAD Scholar who holds a PhD in Early Childhood Studies from Kenyatta University. Her research interest is on caregiving practices for the under-threes, children's early literacy skills, orphans and vulnerable children, as well as parental involvement in their children's development and education.

mwoma.teresa@ku.ac.ke 
Recent publications include:

Mwoma, T. (2019), 'Preschool Attendance and Children's Reading Ability: A Case of Narok County Kenya', International Education Journal: Comparative Perspectives, 17(4): 83-96.

Mwoma, T., Begi, N. \& Murungi, C. (2018), 'Safety and Security in Preschools: A Challenge in Informal Settlements', Issues in Educational Research, 28(3): 720-36.

Mwoma, T. (2017), 'Children's Reading Ability in Early Primary Schooling: Challenges for a Kenyan Rural Community', Issues in Educational Research, 27(2): 347-264.

Mwoma, T. \& Pillay, J. (2016), 'Educational Support for Orphans and Vulnerable Children in Primary Schools: Challenges and Interventions', Issues in Educational Research, 26(1): 82-97.

Mwoma, T. \& Pillay, J. (2015), 'Psychosocial Support for Orphans and Vulnerable Children in Public Primary Schools: Challenges and Intervention Strategies', South African Journal of Education, 35(3): 1-9. https://doi.org/10.15700/saje.v35n3a1092

Elizabeth $W$ Kimani-Murage is a Public Health Specialist and a Senior Research Scientist at the African Population and Health Research Centre (APHRC), Nairobi, Kenya. She was the Kenyan Lead investigator for the British Academy funded early child development project entitled 'Testing the Feasibility of Incorporating Support for Early Child Development into The Baby Friendly Community Initiative in Kenya'. She leads implementation/evaluation research on strategies to improve maternal and child nutrition, health and well-being, using both quantitative and qualitative methods. These strategies include the Baby Friendly Community Initiative (BFCI); human milk banking; community-based management of acute malnutrition; workplace support for breastfeeding and childcare; and integration of early child development services into the health care system.

Recent publications include:

Kimani-Murage, E. W., Wanjohi, M. N., Kamande, E., Macharia, T., Mwaniki, E., Zerfu, T., Ziraba, A., Muiruri, J., Samburu, B., Govoga, A., Kiige, L., Ngwiri, T., Mirie, W., Musoke, R., Mansen, K. \& Israel-Ballard, K. (2019), 'Perceptions and Acceptability of Donating and Use of Donated Human Milk and Human Milk Banking in Nairobi, Kenya', Maternal and Child Nutrition, 15(4): e12842. https://doi.org/10.1111/mcn.12842

Nyamasege, C. K., Kimani-Murage, E. W., Wanjohi, M., Mulwa, D. W., Ma, E. Fukushige, M. \& Wagatsuma, Y. (2019), 'Determinants of Low Birth Weight in the Context of Maternal Nutrition Education in Urban Informal Settlements, Kenya', Journal of Developmental Origins of Health and Disease, 10(2): 237-45. https://doi.org/10.1017/S2040174418000715

Cheikh Faye Sharon Fonn, Levin, Jonathan \& Kimani-Murage, Elizabeth (2019), 'Analyzing Child Linear Growth Trajectories Among Under-5 Children in Two Nairobi Informal Settlements', Public Health Nutrition, 22(11): 2001-11. https://doi.org/10.1017/S1368980019000491

Paula Griffiths is Professor of Population Health at Loughborough University and was the lead investigator for the British Academy funded early child development project entitled; 'Testing the Feasibility of Incorporating Support for Early Child Development into The Baby Friendly Community Initiative in Kenya'. Professor 
Griffiths undertakes research to support the development of community-based health programmes that reduce inequalities. She has been working closely with collaborators at the African Population and Health Research Centre, Kenyatta University and the Ministry of Health for more than five years, producing evidence that has supported the roll-out of the Baby Friendly Community Initiative in Kenya

To cite the article: Teresa Mwoma, Patricia Kitsao-Wekulo, Emma Haycraft, Elizabeth Kimani-Murage, Milka Wanjohi, Judith Kimiywe, Esther Kinuthia, Peter Muriuki, Natalie Pearson, Kenneth Okelo, Silas Onyango, Oscar Kadenge, Betty Samburu, Stephen Mwangi, Stewart Kabaka, Charity Tauta and Paula Griffiths (2019), 'Experiences of incorporating support for early childhood development into the Baby Friendly Community Initiative in rural Kenya', Journal of the British Academy, 8(s2): 103-132.

DOI https://doi.org/10.5871/jba/008s2.103

Journal of the British Academy (ISSN 2052-7217) is published by The British Academy, 10-11 Carlton House Terrace, London, SW1Y 5AH www.thebritishacademy.ac.uk 